\title{
DIFFUSION COEFFICIENTS IN MOMENTUM FOR A RELATIVISTIC ELECTRON BEAM IN AN UNDULATOR
}

\author{
V.V. Ognivenko \\ National Science Center “Kharkov Institute of Physics and Technology”, Kharkiv, Ukraine \\ E-mail: ognivenko@kipt.kharkov.ua
}

We consider a motion of a relativistic electron beam in a spatially periodic magnetic field of an undulator taking into account the influence of the spontaneous radiation fields on this motion. The diffusion coefficients in longitudinal momentum of electrons are found. It is shown that in initially monoenergetic electron beam a mean square spread due to influence of the incoherent fields on electron motion may have a predominant effect compared with the spread caused by the quantum fluctuations.

PACS: 41.60.-m, 41.60.Cr, 52.25.Gj

\section{INTRODUCTION}

Charged particles, moving in a spatially periodic static magnetic field of undulator, radiate electromagnetic waves. Self amplification of these waves in a beam of ultrarelativistic electrons is the physical mechanism underlying operation of a X-ray FEL [1 - 4]. In such devices a high density electron beam should have small energy spread. At the initial stage of the stimulated radiation formation in a FEL, in a spontaneous radiation mode, the electrons radiate independently. The influence of this incoherent field on the electrons motion leads to the increase in momenta spread of electrons [5]. This effect is connected with the discrete structure of the electron beam and is described by pair interaction of the particles through the electromagnetic fields created by them. The investigation of the momenta spread in the electron beam which is monoenergetic at an undulator entrance, is curried out in [5].

In the present paper the expressions for the diffusion coefficient in a longitudinal momentum for the beam of ultrarelativistic electrons with initial longitudinal momentum spread at the undulator entrance are obtained. The numerical calculations of the equations describing increase of momentum spread in an initially monoenergetic ultrarelativistic electron beam and the comparison of this spread with the spread caused by the quantum effects are presented.

\section{THE BASIC EQUATIONS}

We consider helical undulator with magnetic field

$$
H_{u}=H_{0}\left[\mathbf{e}_{x} \cos \left(k_{u} z\right)+\mathbf{e}_{y} \sin \left(k_{u} z\right)\right\rfloor,
$$

where $k_{u}=2 \pi / \lambda_{u}, \mathrm{H}_{0}$ and $\lambda_{u}$ are the amplitude and period of magnetic field, $\mathbf{e}_{x}, \mathbf{e}_{y}$ are the unit vectors along axes $\mathrm{x}$ and $\mathrm{y}$ of the Cartesian system of coordinates.

Let the relativistic electron beam with average density $\mathrm{n}_{\mathrm{b}}$ cross the plane $\mathrm{z}=0$ and move in the positive direction of the axis $z$. The equations of longitudinal motion of an individual electron in the field of undulator and the fields created by other electrons of a beam take the form:

$$
\begin{gathered}
\frac{d \mathrm{p}_{z i}}{d t}=\sum_{s} F_{z}^{(s)}\left[x_{i}(t), t ; x_{s}\right], \\
F_{z}^{(s)}\left(x, t ; x_{s}\right)=e\left\{\mathrm{E}_{z s}\left(x, t ; x_{s}\right)+\frac{1}{c}\left[\mathbf{v} \mathbf{H}_{s}\left(x, t ; x_{s}\right)\right]_{z}\right\},
\end{gathered}
$$

where $p_{z}=m \mathrm{v}_{z} \gamma, F_{\mathrm{z}}^{(\mathrm{s})}\left(x_{i}, \mathrm{t} ; x_{\mathrm{s}}\right)$ is the longitudinal component of the pair interaction force of two electrons, $\mathrm{m}$ is the mass of electron, $\mathrm{x}_{\mathrm{s}} \equiv\left\{\mathbf{r}_{\mathrm{s}}, \mathbf{p}_{\mathrm{s}}\right\}$ is the set of the coordinates and momentum of $s$-th electron, $E_{s} H_{s}$ are the electric and magnetic fields produced by an individual electron (s-th) in the undulator, $\gamma=\left(1-\beta^{2}\right)^{-1 / 2}, \mathrm{c}$ is the velocity of light, e is the electron charge.

The diffusion coefficient in the longitudinal momentum, caused by the interaction of electrons through the electromagnetic fields created by them, is [5]:

$$
\begin{aligned}
& D_{z}=\frac{d}{2 d t}\left\langle\left(\Delta p_{z i}\right)^{2}\right\rangle=\int_{0}^{\tau} d \tau^{\prime} \int_{\Omega q} F_{z}^{(s)}\left[x_{i}(t), t ; x_{s}\left(t, q_{0 s}\right)\right] \times \\
& \times F_{z}^{(s)}\left[x_{i}\left(t-\tau^{\prime}\right), \tau^{\prime} ; x_{s}\left(t-\tau^{\prime}, q_{0 s}\right)\right] \times \\
& \times f\left(p_{s}\right) \mathrm{v}_{z s}\left(t_{0 s}\right) d q_{0 s},
\end{aligned}
$$

where $\mathrm{q}_{0 \mathrm{~s}}=\left(\mathbf{p}_{\mathrm{s}}, \mathrm{x}_{0 \mathrm{~s}}, \mathrm{y}_{0 \mathrm{~s}}, \mathrm{t}_{0 \mathrm{~s}}\right), \mathrm{dq}_{0 \mathrm{~s}}=\mathrm{dp}_{\mathrm{s}} \mathrm{dx}_{0 \mathrm{~s}} \mathrm{dy}_{0 \mathrm{~s}} \mathrm{dt}_{0 \mathrm{~s}}, \tau=\mathrm{t}-\mathrm{t}_{0 \mathrm{i}}$, $f$ is the distribution function of electrons, $x_{i}=\left(\mathbf{r}_{i}, \mathbf{p}_{i}\right)$.

In the case of small undulator parameter $\mathrm{K}^{2}<<1$ the expression for the longitudinal components of the force acting on $i$ th electron in the field of $s$ th electron is

$$
\begin{aligned}
& F_{z}^{(s)}\left(\mathbf{r}_{i}, t ; q_{0 s}\right)=-\frac{\left(e \mathrm{~K} k_{u} \gamma_{s}^{2} / \gamma_{i}\right)^{2}}{k_{0 s} R_{*}} \times \\
& \times\left[\left(\beta_{s}+\frac{\Delta z_{s i}}{R_{*}}-\frac{\beta_{s} \rho_{s i}^{2}}{k_{0 s}^{2} R_{*}^{2} \gamma_{z}^{2}}\right) \sin \psi+,\right. \\
& \left.+\left(\beta_{s}+\frac{\Delta z_{s i}}{R_{*}}\right) \frac{\cos \psi}{k_{0 s} R_{*}}\right]
\end{aligned}
$$

where $\psi=k_{u} \gamma_{z s}^{2}\left(\Delta z_{s i}+\beta_{s} R_{*}\right), R_{*}=\sqrt{\left(\Delta z_{s i}\right)^{2}+\rho_{s i}^{2} / \gamma_{z 0}^{2}}$, $\Delta z_{s i}=z_{i}-\mathrm{v}_{z s}\left(t-t_{0 s}\right), \rho_{s i}=\left|\mathbf{r}_{\perp i}-\mathbf{r}_{\perp s}\right|, k_{0 s}=\beta_{s} \gamma_{z s}^{2} k_{u}$, $\beta=\mathrm{v} / c$, symbol " $\perp$ " denotes the vector perpendicular to axes $\mathrm{z}, K=|e| H_{0} /\left(m c^{2} k_{u}\right), \gamma_{z}=\gamma_{0} / \sqrt{1+K^{2}}$.

The integration limits in the equation (4) are defined by both the time of front propagation of radiation field from $\mathrm{s}$ th electron and the beam size

$$
\begin{aligned}
& \Delta z_{i s}+\beta_{i}\left((\Delta z)_{s i}^{2}+\rho_{s i}^{2} / \gamma_{s}^{2}\right)^{1 / 2} \leq z / \gamma_{i}^{2} \\
& \left(x_{o s}^{2}+y_{0 s}^{2}\right)^{1 / 2} \leq r_{b}
\end{aligned}
$$

Here we assume that the beam is continuous cylindrical with radius $r_{b}$ and the coordinate $\mathrm{z}$ is chosen as an independent variable.

Let's assume that the distribution function of electrons at the undulator entrance $(\mathrm{z}=0)$ is: 


$$
f\left(\mathbf{p}_{s}\right)=\frac{n_{b}}{\sqrt{2 \pi} p_{t h}} \delta\left(\mathbf{p}_{\perp s}\right) \exp \left[-\frac{\left(p_{z s}-p_{z 0}\right)^{2}}{2 p_{t h}^{2}}\right],
$$

where $p_{t h}$ is the initial thermal spread in the longitudinal momentum.

We will take into consideration the radiation fields of electrons (s-th) emitted in the direction of the beam motion and find diffusion coefficient in the momentum for electrons moving near the axis $\mathbf{r}_{0 \perp i}=0$.

Depending on the initial distribution in momenta of electrons it is possible to separate two stages of the process of the momentum spread increase in a beam moving in the undulator.

With the distances $z<<\lambda_{u} p_{z 0} / p_{t h}$ the influence of thermal spread in momentum in the beam can be neglected [6]. In this case the motion of electrons in undulator occurs under the influence of pair interaction forces which do not depend on the distance $z$. At this stage the diffusion coefficient, at $z \gg r_{b} \gamma_{z 0}$, takes the form [5]:

$$
D_{z}=\pi^{2} e^{4} K^{4} n_{b} k_{u}^{2} r_{b} \gamma_{z 0} z / \mathrm{v}_{z},
$$

and the mean square value of the longitudinal momentum spread increases proportionally to a distance square

$$
\left\langle\left(\Delta p_{z}\right)_{\text {rad }}^{2}\right\rangle=\pi^{2}(m c)^{2} r_{e}^{2} n_{b} r_{b} \gamma_{z 0} K^{4}\left(k_{u} z\right)^{2},
$$

where $r_{e}=e^{2} /\left(m c^{2}\right)$.

In the opposite limiting case of greater distances $z>>\lambda_{u} p_{z 0} / p_{t h}$ the motion of particles is random and, consequently, the diffusion coefficient in the momentum does not depend on the distance covered by the beam [6]. Substituting the expressions for the force (5) and the distribution functions (7) in the equation (4) and integrating into this equation on initial coordinates of electrons, satisfying the equation (6), we can obtain the following asymptotic formulas for the diffusion coefficient in momentum space:

at $\left|p_{z}-p_{z 0}\right| \ll p_{t h}$ and

$$
D_{z}\left(p_{z}\right)=\pi^{3 / 2} \sqrt{2} e^{4} K^{4} k_{u} r_{b} \gamma_{z 0} \frac{n_{b}}{\mathrm{v}_{z}} \frac{p_{z 0}}{p_{t h}},
$$

$$
D_{z}\left(p_{z}\right)=3 \pi e^{4} K^{4} \frac{n_{b}}{\mathrm{v}_{z}}\left(\frac{r_{b} \gamma_{z 0} p_{z 0}}{z\left(p_{z}-p_{z 0}\right)}\right)^{2},
$$

at $\left|p_{z}-p_{z 0}\right| \gg>p_{t h}$.

In this case the mean square spread in momentum will increase proportionally to the distance in the first degree $\left\langle\left(\Delta p_{z}\right)^{2}\right\rangle \sim z$.

As for ultrarelativistic particles the momentum spread is related to the energy spread by: $\left\langle\left(\Delta p_{z}\right)^{2}\right\rangle=m^{2} \mathrm{v}_{z}^{2}\left\langle(\Delta \gamma)^{2}\right\rangle$, then the growth of momentum spread corresponds to the growth of the energy spread in a beam.

\section{NUMERICAL SIMULATION}

For the realization of self amplification of spontaneous emission in an X-ray FEL it is necessary, that at the entrance of the undulator the electrons had small energy spread, i.e. were monoenergetic. Therefore we will consider the change of a mean square spread in momenta of electrons in such a beam, assuming that $f\left(p_{s}\right)=n_{b} \delta\left(p_{\perp s}\right) \delta\left(p_{z s}-p_{z 0}\right)$ at $\mathrm{z}=0$. The Eq. (4) with such distribution function and with pair interaction force (5) will have the form

$$
\begin{aligned}
& \left\langle\left(\Delta p_{z}\right)^{2}\right\rangle=4 \pi\left(m c r_{e} K k_{u} \gamma_{z 0}^{3} / \gamma_{0}^{2}\right)^{2} n_{b} \times \\
& \times \int_{0}^{z} d z^{\prime}\left(z-z^{\prime}\right) \int_{0}^{\pi / 2} d \theta \sin \theta \int_{0}^{r_{\max }^{\prime}\left(z^{\prime}\right)} d r^{\prime} g^{2}\left(r^{\prime}, \theta\right)
\end{aligned}
$$

where $g=\left(\beta_{z 0}+\cos \theta-\frac{\beta_{z 0}}{k_{0}^{2} r^{\prime 2}}-\frac{1}{2} \beta_{z 0} \sin ^{2} \theta\right) \sin \psi+$

$+\left(\beta_{z 0}+\cos \theta\right) \frac{\cos \psi}{k_{0} r^{\prime}}, \quad r^{\prime}=R_{*}, \quad \theta=\operatorname{arcctg}\left(\frac{\gamma_{z 0} \Delta z_{s i}}{\rho_{s i}}\right)$,

$\psi=\gamma_{z 0}^{2} k_{u}^{2}\left(\beta_{z 0}+\cos \theta\right)$.

The limits of integration are defined by Eq. (6).

Figs. 1, 2 show the result of the numerical calculation of the Eq. (12). Calculations are carried out for the following parameters of the beam: peak current $\mathrm{I}_{\mathrm{p}}=4 \mathrm{kA}, \mathrm{r}_{\mathrm{b}}=70 \mu \mathrm{m}$ and the undulator $\mathrm{H}_{0}=0.15 \mathrm{~T}$, $\lambda_{\mathrm{u}}=3 \mathrm{~cm}$. In the Fig. 1 the normalized mean square spread in momentum of electrons $\left\langle(\Delta \gamma)^{2}\right\rangle=\left\langle\left(\Delta p_{z}\right)^{2}\right\rangle /(m c)^{2}$ is plotted as the function of the distance covered by them in undulator for several wavelength values of radiation $\lambda=\lambda_{u} /\left(2 \gamma_{z 0}^{2}\right)$. The curves 1,2 and 3 correspond to the value of the initial energy of electron $E_{b}=m c^{2} \gamma_{0}: 9.6,6.79$ and $5.54 \mathrm{GeV}$, respectively.

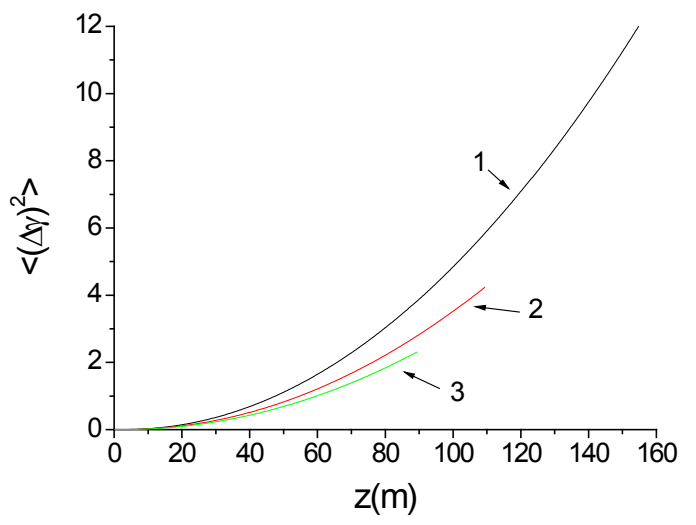

Fig. 1. Spatial evolution of the normalized energy, spread for various radiation wavelengths (1) $0.5 \AA$,

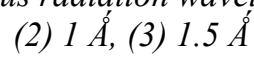

The dependences of energy spread on coordinate $\mathrm{z}$ have been calculated up to values equal $z_{\text {sat }}=\lambda_{u} / \rho_{1 D}$, which correspond to a saturation length in a FEL, where $\rho_{1 D}=\frac{1}{\gamma_{0}}\left(\frac{K^{2} n_{b} r_{e} \lambda_{u}^{2}}{16 \pi}\right)^{1 / 3}$.

Fig. 1 shows that the momentum spread increases as the function of distance along the axis $\mathrm{z}$ and that the energy spread increases with the growth of electrons initial energy.

When a charge moves in an undulator their energy spread can also increase because of quantum fluctuations [7]. In the case of $K<<1$ it is possible to present the value of this spread in the form

$$
\left\langle(\Delta \gamma)_{q f}^{2}\right\rangle=\frac{14}{15} \lambda_{c} \gamma^{4} k_{u}^{3} K^{2} z
$$


where $\lambda_{c}=\hbar / m c$

Using the formula (9) we will write down

$$
\frac{\left\langle(\Delta \gamma)_{\text {rad }}^{2}\right\rangle}{\left\langle(\Delta \gamma)_{q f}^{2}\right\rangle}=\frac{15 \pi}{28} \alpha \frac{K^{2} \lambda_{u} r_{b}}{\sqrt{1+K^{2}}} \frac{n_{b}}{\gamma^{3}} z,
$$

where $\alpha=\frac{r_{e}}{\lambda_{c}}=\frac{e^{2}}{\hbar c}=7.297 \cdot 10^{-3}$ is the fine structure constant.
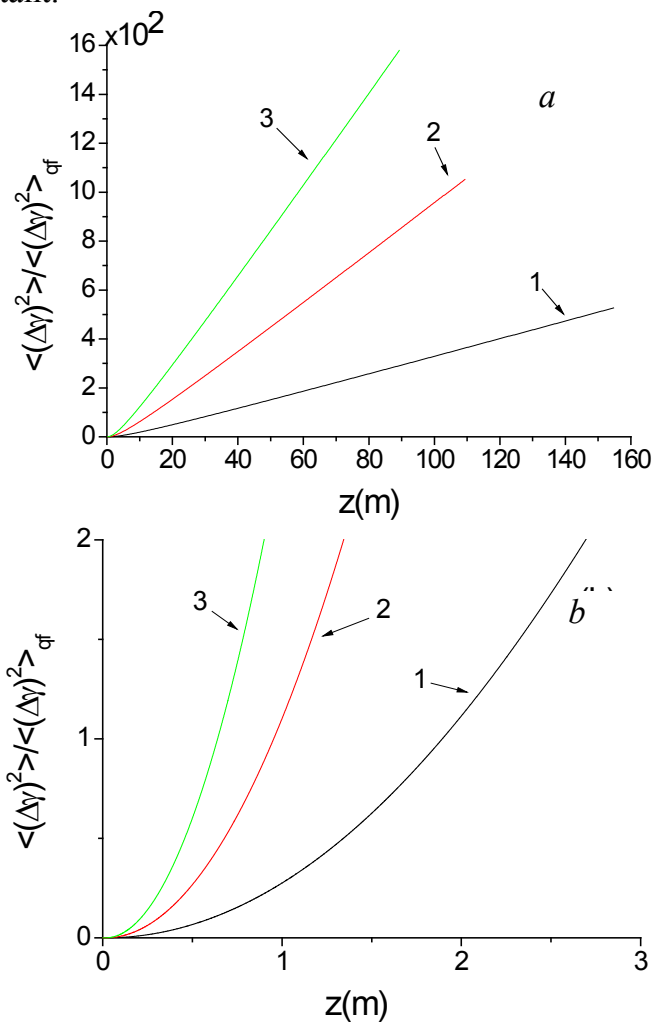

Fig. 2. Ratio of energy spread obtained from the simulation and energy spread due to quantum fluctuations obtained from Eq. (13) as a function of the interaction dis-

tance. The curves 1, 2 and 3 correspond to the value of the radiation wavelength $0.5,1$ and $1.5 \AA$, respectively

Although quantum fluctuations increase proportionally to the fourth degree of electron energy, the energy spread due to radiation interaction of electrons in a dense beam may be greater than the spread caused by quantum fluctuations.

Fig. 2 presents spatial evolution of the ratio of the energy spread obtained from the numerical simulationof Eq. (12) and the energy spread caused by the quantum fluctuations of the radiation obtained from the
Eq. (13). Fig. 2,b presents the plot of the initial segments of the same curves as in Fig. 2,a. It is seen from Fig. 2 that the growth rate of the energy spread due to radiation interaction of electrons is more than the growth rate of the energy spread caused by the quantum fluctuations. If the distance $\mathrm{z}$ is too small, quantum effects will become important.

\section{CONCLUSIONS}

In this paper the influence of incoherent fields of spontaneous radiation on the mean square momentum change of electrons at spontaneous emission mode are examined. It is shown that the mean square longitudinal momentum spread of electrons due to classical (nonquantum) radiating effects, as well as the energy spread of electrons, increase when the electron beam moves in undulator. From the presented calculations it follows, that in the initially monoenergetic electron beam the growth rate of the energy spread due to the radiation effect is greater than the growth rate of the energy spread caused by quantum effects. Thus, the influence of incoherent fields of spontaneous radiation of electrons on their motion in undulator leads to the increase in the energy spread in the electron beam and can hinder the decrease of coherent radiation wavelength in a X-ray FEL.

\section{REFERENCES}

1. V. Ayvazyan et al. First operation of a free-electron laser generating GW power radiation at $32 \mathrm{~nm}$ wavelength // Eur. Phys . J. D. 2006, v. 37, p. 297-303.

2. P. Emma et al. First Lasing and Operation of an Ångstrom-Wavelength Free-Electron Laser // Nature Photonics. 2010, v. 4, p. 641-647.

3. S.T. Ishikawa et al. A compact X-ray free-electron laser emitting in the sub-ångström region // Nature Photonics. 2012, v. 6, p. 540-544.

4. H. Weise, W. Decking. Commissioning and first lasing of the European XFEL // Proc. 38-th Free-Electron Laser Conf. Santa Fe, NM, USA. 2017, p. 9-13.

5. V.V. Ognivenko. Momentum spread in a relativistic electron beam in an undulator // J. Exp. Theor. Phys. 2012, v. 115, № 5, p. 938-946.

6. V.V. Ognivenko. Radiative relaxation of relativistic electron beam in helical undulator // Problems of Atomic Science and Technology. 2017, № 6, p. 85-87.

7. J. Rossbach, E.L. Saldin, E.A. Schneidmiller, M.V. Yurkov. Interdependence of parameters of X-ray FEL // Nucl. Instum. and Methods. 1996, A374, p. 401-407.

Article received 01.10.2019

\section{КОЭФФИЦИЕНТ ДИФФУЗИИ ПО ИМПУЛЬСАМ В ПОТОКЕ РЕЛЯТИВИСТСКИХ ЭЛЕКТРОНОВ В ОНДУЛЯТОРЕ}

\section{В.В. Огнивенко}

Рассмотрено движение ультрарелятивистского электронного пучка в пространственно-периодическом магнитном поле ондулятора с учетом влияния полей спонтанного излучения на это движение. Получено выражение для продольного коэффициента диффузии. Показано, что в первоначальном моноэнергетическом электронном потоке среднеквадратичный разброс, обусловленный влиянием некогерентных полей спонтанного излучения на движение электронов, может превышать разброс, обусловленный квантовыми флуктуациями.

\section{КОЕФІЦІНТ ДИФУЗЇ̈ ПО ІМПУЛЬСАХ У ПОТОЦІ РЕЛЯТИВІСТСЬКИХ ЕЛЕКТРОНІВ В ОНДУЛЯТОРІ}

\section{В.В. Огнівенко}

Розглянуто рух ультрарелятивістського електронного пучка в просторово-періодичному магнітному полі ондулятора 3 урахуванням впливу полів спонтанного випромінювання на цей рух. Отримано вираз для поздовжнього коефіцієнта дифузії по імпульсах. Показано, що в початковому моноенергетичному електронному потоці середньоквадратичний розкид, обумовлений впливом некогерентних полів спонтанного випромінювання на рух електронів, може перевищувати розкид, обумовлений квантовими флуктуаціями. 